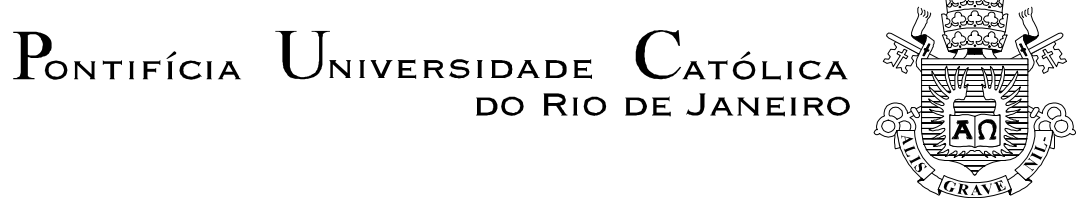

Mariana Schultz Moreeuw

\title{
Aspectos verbais e não-verbais em pedidos de informação no português do Brasil - Uma aplicabilidade ao ensino de PL2E
}

Dissertação de Mestrado

Dissertação apresentada como requisito parcial para obtenção do título de Mestre pelo Programa de Pós-Graduação em Letras da PUC-Rio.

Orientadora: Prof ${ }^{a}$. Adriana Ferreira de Souza de Albuquerque 
Pontifícia Universidade Católica DO RIO DE JANEIRO

\title{
Mariana Schultz Moreeuw
}

\begin{abstract}
Aspectos verbais e não-verbais em pedidos de informação no português do Brasil Uma aplicabilidade ao ensino de PL2E
\end{abstract}

Dissertação apresentada como requisito parcial para obtenção do grau de Mestre pelo Programa de Pós-Graduação em Letras do Departamento de Letras do Centro de Teologia e Ciências Humanas da PUC-Rio. Aprovada pela Comissão Examinadora abaixo assinada.

Profa. Adriana Ferreira de Sousa de Albuquerque Orientadora Departamento de Letras - PUC-Rio

Profa. Rosa Marina de Brito Meyer Departamento de Letras - PUC-Rio

Profa. Maria Teresa Gonçalves Pereira UERJ

Prof. Paulo Fernando Carneiro de Andrade Coordenador Setorial do Centro de Teologia e Ciências Humanas - PUC-Rio

Rio de Janeiro, de de 
Todos os direitos reservados. É proibida a reprodução total ou parcial do trabalho sem autorização da universidade, da autora e da orientadora.

\section{Mariana Schultz Moreeuw}

Graduou-se Bacharel em Letras Português e Francês pela Universidade Federal do Rio de Janeiro em 2003. Concluiu os estudos de licenciatura plena na mesma universidade em 2005. Participou do programa Assistants étrangers en France, lecionando a língua portuguesa no Lycée Montaigne, em Paris (ano letivo 2005/2006). Atua no ensino de francês (LE) e de português (L2E e LM).

Ficha Catalográfica

Moreeuw, Mariana Schultz

Aspectos verbais e não-verbais em pedidos de informação no português do Brasil : uma aplicabilidade ao ensino de PL2E / Mariana Schultz Moreeuw ; orientadora: Adriana F. de Souza de Albuquerque. - 2009.

140 f. : il. (color.) ; $30 \mathrm{~cm}$

Dissertação (Mestrado em Letras)-Pontifícia Universidade Católica do Rio de Janeiro, Rio de Janeiro, 2009.

Inclui bibliografia

1. Letras - Teses. 2. Atos da fala. 3. Pedidos de informação. 4. Língua portuguesa. 5. Cultura brasileira. 6. Português do Brasil como PL2E. 7. Linguagem verbal. 8. Linguagem não verbal. I. Albuquerque, Adriana F. de Souza de. II. Pontifícia Universidade Católica do Rio de Janeiro. Departamento de Letras. III. Título. 


\section{Agradecimentos}

Primeiramente a Deus, por todas as bênçãos.

À minha família, especialmente à minha mãe Luzia Helena que sempre acreditou em minha capacidade.

Ao meu companheiro Jorge Eduardo pela paciência e carinho.

Aos meus amigos, em especial, Ângela, Márcia e Edmar, pelas oportunidades e pelo incentivo e compreensão.

À Puc-Rio pela bolsa de isenção acadêmica concedida.

À professora Rosa Marina de Brito Meyer pelo convite de participar dos Estudos de PL2E desta universidade.

À professora e orientadora Adriana F. de Sousa de Albuquerque pela orientação e incentivo.

Aos professores que contribuíram para a minha formação acadêmica.

Aos professores que participaram da Comissão Examinadora.

Aos amigos do departamento de Letras da Puc-Rio, em especial à Chiquinha e às professoras Telma Pereira e Denise Lezan.

Muito obrigada! 


\section{Resumo}

Moreeuw, Mariana Schultz; Albuquerque, Adriana Ferreira de Souza (orientadora). Aspectos verbais e não-verbais em pedidos de informação no português do Brasil - Uma aplicabilidade ao ensino de PL2E. Rio de Janeiro, 2009. 140p. Dissertação de Mestrado Departamento de Letras, Pontifícia Universidade Católica do Rio de Janeiro.

O presente trabalho tem o objetivo de mostrar os aspectos verbais e nãoverbais em pedidos de informação no português do Brasil. Para tal, a base teórica deste estudo concentrou-se nos conceitos da Pragmática - a Teoria dos Atos de Fala e a Sociolinguística Interacional; nos conceitos da Antropologia Social e do Interculturalismo. A análise de dados baseia-se em um corpus formulado por estudantes de uma universidade da Zona Sul do Rio de Janeiro, no qual se encontram formulações verbais de pedidos de informação em contexto universitário, assim como as reações e opiniões dos informantes em relação aos aspectos não-verbais de tais pedidos. A apreciação do corpus permitiu a identificação de algumas estruturas que compõem os pedidos de informação e, também, a verificação da relevância dos atos de tocar e de gesticular no momento em que o brasileiro pede uma informação. Para um melhor aproveitamento deste estudo, observou-se como o tema desta pesquisa é abordado em livros didáticos de PL2E e, por fim, sugeriu-se uma atividade aplicável ao ensino do português do Brasil como segunda língua para estrangeiros ou como língua estrangeira.

\section{Palavras-chave}

Atos de fala; pedidos de informação, língua portuguesa, cultura brasileira, português do Brasil como PL2E, linguagem verbal, linguagem não-verbal 


\section{Résumé}

Moreeuw, Mariana Schultz; Albuquerque, Adriana Ferreira de Souza (orientatrice). Aspects verbaux et non verbaux des demandes d'information en portugais du Brésil - une applicabilité à l'enseignement de PL2E. Rio de Janeiro, 2009. 140p. Dissertation de Master - Departamento de Letras, Pontifícia Universidade Católica do Rio de Janeiro.

Ce travail a l'objectif de montrer les aspects verbaux et non verbaux en demandes d'information au portugais du Brésil. Pour tel but, la base théorique de cette étude se concentre sur les concepts de la Pragmatique - la théorie des actes de parole et de la sociolinguistique interacionelle - ; sur les concepts de l'anthropologie sociale et aussi sur le concept de l'interculturalisme. L'analyse de données est faite a partir d'un corpus, formulé par des étudiants d'une université de la Zone Sud de Rio de Janeiro, dans lequel se trouvent des formulations verbaux de demandes d'informations dans contexte universitaire, tandis que les réactions et les avis des informateurs concernant les aspects non verbaux de telles demandes. L'appréciation du corpus nous a permis l'identification des structures des demandes d'informations et, aussi, la vérification de l'importance des actes de toucher et de gesticuler au moment où le brésilien demande des informations. Pour une meilleure exploitation de cette étude, on a observé de quelle manière le sujet de cette recherche est abordé dans des livres didactiques de PL2E et, finalement, on a suggéré une activité applicable à l'enseignement du Portugais du Brésil comme seconde langue pour étrangers ou comme langue étrangère.

\section{Mots cléfs}

Actes de parole; demande d'information, langue portugaise, culture brésilienne, portugais du Brésil, PL2E, langage verbal, langage non verbal 


\section{Sumário}

1. Introdução 09

1.1. Justificativa 10

1.2. O problema 11

1.3. Objetivos 11

1.4. Relevância 12

1.5. Organização dos capítulos 12

2. Aspectos teóricos e metodológicos $\quad 14$

2.1 Fundamentos teóricos 14

2.1.1. Conceitos da Pragmática 15

2.1.1.1. Os atos de fala 15

i. Os atos de fala: pedidos de informação 15

$\begin{array}{ll}\text { ii. Diretividade e indiretividade } & 17\end{array}$

iii. Os pré-pedidos de informação 20

$\begin{array}{ll}\text { 2.1.1.2. Estratégias de polidez } & 21\end{array}$

i. Mitigação e o aumento da força ilocucionária 23

2.1.1.3. A relação da indiretividade / diretividade com a polidez em pedidos de informação $\quad 24$

2.1.1.4. A interação não-verbal 26

2.1.2. Conceitos da Antropologia Social 28

2.1.2.1. Afetividade - A Casa e a Rua 30

2.1.3. Interculturalismo 31

2.1.3.1. Português: uma língua de alto contexto 33

2.2. Fundamentos metodológicos $\quad 34$

3. Análise de dados $\quad 35$

3.1. O pré-pedido de informação 35

3.2. O pedido de informação 37

3.2.1. Abrindo o canal de comunicação - Aspectos verbais 37 
3.2.2. Abrindo o canal de comunicação - Aspectos não-verbais: a importância dos gestos e do toque 39

3.2.3. Pedindo a informação 42

3.2.4. Resumindo 46

3.2.5. Estrutura do ato de fala ilocucionário de pedido de informação 47

4. O ato de fala de pedidos de informação em materiais didáticos de PL2-E: uma análise crítica

5. Pedido de informação em contexto universitário: uma proposta de aplicabilidade ao ensino de português do Brasil como L2E 68

6. Considerações finais $\quad 80$

7. Referências bibliográficas 83

8. Anexos 86 